\title{
Analysis of Value Creation Process of Platform-driven Scientific and Technological Innovation Value Chain: the Perspective of Informationization
}

\author{
SHENG Ya ${ }^{1 \text { st }}$, LIU Yue ${ }^{2 n d *}$, ZHANG Shu Man ${ }^{3 r d}$ \\ ${ }^{1 \text { st }}$ School of Business Administration Zhejiang Gongshang University Hangzhou, China \\ ${ }^{2 n d}$ School of Business Administration Zhejiang Gongshang University Hangzhou, China \\ ${ }^{3 r d}$ School of Business Administration Zhejiang Gongshang University Hangzhou, China
}

\begin{abstract}
At present, the innovation environment of science and technology innovation platform is constantly changing, which has gradually changed from the situation of science and technology innovation among single elements to the information comparison among the whole innovation value chain. In this paper, science and technology innovation platform is divided into four types: pure research platform, industrial technology research platform, business incubation platform and public service platform. It deeply analyzes the informationization process of innovation value chain driven by science and technology innovation platform, including basic research, applied research, experimental development and commercialization. By analyzing the role of knowledge capital, technology capital, venture capital and other information resources in science and technology innovation platform, it explores the value flow among platforms. It is found that the stock capital and variable capital of scientific and technological innovation are not a transformation, but realize the increment and cyclic accumulation of income along the innovation chain step by step. The research expands the analysis scope of informatization theory, combs the value creation process of science and technology innovation platform, and contributes to risk avoidance and benefit distribution.
\end{abstract}

\section{INTRODUCTION}

With the continuous improvement of China's scientific and technological innovation capability, the international influence of basic research and applied research has been greatly strengthened, and the construction of scientific and technological innovation platform is constantly improving. Since the 13th Five-Year Plan, China has entered a decisive period of building a well-off society in an allround way and entering the ranks of innovative countries. In this critical period of building the world into a powerful country in science and technology, it is necessary to implement the strategy of innovation-driven development in depth and deepen the reform of science and technology system in an all-round way to enhance scientific and technological innovation. The innovation environment is constantly changing, which has gradually changed from the technological innovation situation among individual elements to the comparison among the whole innovation value chain, with each link in the chain progressing step by step to promote value increment. The Fifth Plenary Session of the 19th CPC Central Committee pointed out that the focus of self-reliance of science and technology lies in breaking through key core technologies, effectively solving the connection between the "first mile" of knowledge innovation and the "last mile" of technological innovation and commercial application, and opening up the value chain of scientific and technological innovation. The construction of scientific and technological innovation platform, bearing the important mission of $\mathrm{R} \& \mathrm{D}$, application and marketization, is an important measure of China's innovation construction, and plays an important role in improving national innovation capability and opening up the value chain of scientific and technological innovation.

At present, the research on science and technology innovation platform is more about the concept of science and technology innovation platform [2], the analysis of the main body of science and technology innovation platform construction [3-4], and the research on innovation efficiency and evaluation system of science and technology innovation platform [5-6], but less about the combination of its classification and value creation. The research on innovation value chain usually focuses on "innovation efficiency" [7], while ignoring "value creation process" [8], ignoring the internal structure of the value chain and becoming a "black box". The innovation value chain highlights the structure and complexity of the process of commercializing knowledge, and emphasizes the role of skills, capital investment and other resources of enterprises in the process of value creation, which is a

* Corresponding author: 5055274@163.com 
multi-stage and multi-input process [9]. Therefore, it is of great theoretical significance to study the value creation process of scientific and technological innovation platform under the innovation value chain.

This study classifies science and technology innovation platforms as a whole, and on the basis of revealing the value chain and value creation process of science and technology innovation platforms, clarifies the value-added process of different types of science and technology innovation platforms, and clarifies the process of knowledge creation and diffusion, which is conducive to risk avoidance and benefit distribution, thus opening the "black box".

\section{The DEFINITION AND CLASSIFICATION OF SCIENCE AND TECHNOLOGY INNOVATION PLATFORM}

The concept of "father" of science and technology innovation platform is the platform. The word "Platform" was first proposed by Henry Ford in Modern Man, which was applied in engineering field. Later, Meyer and other scholars discussed it deeply, and pointed out that platform is a collection of product chain shared data including process, personnel, parts and knowledge, which can be divided into technology platform and product platform [10]. These platforms have basically possessed the functions and functions of innovation platforms, which can not only provide support for research and development, but also help enterprises to formulate core competitive strategies [11]. In 1998, the American Competitiveness Commission pointed out in the report "Going Global: New Situation of American Innovation" that the connotation of innovation platform mainly includes three aspects: First, providing infrastructure and essential innovation resources for innovation activities in the process of innovation, including human resources and knowledge resources; Second, provide necessary conditions for the transformation of innovation achievements, including basic services such as financing and auditing; Three, to provide intellectual property protection and market access for innovation investors to recover their innovation investment. Facing the fierce international competition in science and technology, countries all over the world have made it an important strategic decision to build a first-class scientific and technological innovation platform. Max Planck Institute in Germany, scientific and technological innovation service platform in Ireland and product innovation platform in India are all different practice forms of scientific and technological innovation platform construction [12]. In 2002, China's Ministry of Science and Technology put forward the idea of "a large platform for science and technology" to solve the problem of weak basic conditions for science and technology; In 2006, the Outline of the National
Medium-and Long-Term Science and Technology Development Plan (2006-2020) once again emphasized the importance of scientific and technological infrastructure, and a large number of scientific and technological innovation platforms entered the development period to jointly promote the process of scientific and technological innovation; The 14 th FiveYear Plan and the Outline of Long-term Goals in 2035 in 2021 pointed out that the scientific and technological innovation platform provides reliable support for the high-quality development of science and technology, and it must be based on local conditions and look at the overall situation to realize the effective convergence of innovation chain. Nowadays, the construction of scientific and technological innovation platform has gradually formed a scientific and technological innovation platform system, which is based on R\&D platform, supported by public service platform and focused on industrialization platform, including basic research, applied research, experimental development and commercialization [13].

At the same time, great changes have taken place in the relationship between basic research and applied research. At first, Bacon proposed that scientific research is a single linear model from basic research to applied research, which is irreversible [14]. In 1945, Bush reinforced this statement in the report ScienceEndless Frontier, pointing out that there is an irreconcilable contradiction between basic research and applied research, and applied research always excludes basic research [15]. In the following 40 years, the linear model has been respected by scholars. Until 1990s, American scholar Stokes pointed out that Bush's separation of basic research and applied research was incomplete, ignoring the two-way interaction between basic research and applied research and the diversity of industrial development [16], and according to the attributes of knowledge and application, scientific research was divided into pure basic research, basic research caused by application, pure applied research, skill training and experience arrangement, and scholars had a new understanding of the relationship between them [17]. Based on this technology innovation platform can be divided into pure research platform, industrial technology research platform, business incubation platform and public service platform (Figure 1). The pure research platform mainly carries out basic research and provides theoretical support and knowledge supply for the commercialization and industrialization institutions; Industrial technology research platform is connected with both market and pure research platform, mainly engaged in basic research and applied research for the purpose of commercialization; The business incubation platform conducts pure application research, uses existing basic theories to solve practical problems and incubate hightech enterprises; Public service platform integrates scientific and technological resources and provides 
public services for scientific research and transformation of scientific and technological achievements.

\begin{tabular}{|c|c|c|}
\hline \multirow{4}{*}{ 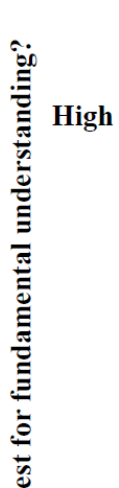 } & \multicolumn{2}{|c|}{ Consideration of use? } \\
\hline & Low & High \\
\hline & $\begin{array}{c}\text { I Pure research } \\
\text { platform }\end{array}$ & $\begin{array}{c}\text { II Industrial } \\
\text { technology research } \\
\text { platform }\end{array}$ \\
\hline & $\begin{array}{c}\text { IV Industrial } \\
\text { technology research } \\
\text { platform }\end{array}$ & $\begin{array}{l}\text { III Entrepreneurship } \\
\text { Incubation Platform }\end{array}$ \\
\hline
\end{tabular}

Figure 1 Types of scientific and technological innovation platforms

\section{SCIENCE AND TECHNOLOGY INNOVATION PLATFORM'S POSITION IN THE INNOVATION VALUE CHAIN}

\subsection{The Evolution of Innovation Chain}

The innovation defined by the early innovation theory begins with the emergence of new technology. Schumpeter believes that innovation is realized in enterprises, new production factors and production conditions are recombined into the production system, and excess profits are realized by developing new products and opening up new markets [18]. Later, Freeman extended the concept of innovation to the creation and diffusion of inventions, and the first introduction of new inventions into commerce was innovation [19],. In their definitions, innovation begins with invention, and invention begins with technological innovation. However, scientific and technological innovation has undergone revolutionary changes,Scholars [20-22] have found that technological progress comes more from knowledge innovation, and the source of innovation has expanded from applied research (technological innovation) to basic research (knowledge innovation), The discovery of new knowledge theory directly or indirectly promotes technological innovation. The speed of scientific and technological achievements from discovery and invention to commercial application is accelerating, and knowledge breakthroughs in the fields of new energy and biotechnology can be rapidly transformed into new technologies to realize industrial development.

General Secretary Xi Jinping pointed out that the transformation from "science" to "technology" has become the main feature of the global scientific and technological revolution,Scientific and technological innovation cannot only stay in the laboratory, but must take the industrialization of major basic research results as the ultimate goal to promote economic development; Only by deploying ahead of time and grasping the three core technologies, such as basic technology, asymmetric technology, cutting-edge technology and disruptive technology, can we realize the transformation of running and leading [23]. This fully shows that the core technology of scientific and technological innovation comes from the basic research stage, and the source of innovation has moved forward to the basic research stage. The difficulty of industrial innovation has changed from technological problems to major scientific problems. This change breaks the boundary between basic research (knowledge innovation) and applied research (technology innovation), and promotes their close connection and integration. Only when the ideas generated in the stage of knowledge innovation enter the innovation system and combine with the stage of technological innovation can the original and subversive technologies be generated to promote the innovation-driven strategy.

Similarly, the end point of scientific and technological innovation has also changed. It is generally believed that as long as there are new patents or inventions, innovation will be realized [24]. However, combined with the current situation of scientific and technological development and the strategic deployment driven by innovation in China, it is far from enough to have new technologies for innovation, Only when new technologies are applied and successfully entered the market to complete commercialization can the innovation stage be fully realized.

The above analysis shows that the process of science and technology innovation chain should start from basic research, that is, knowledge innovation, and complete the commercialization of scientific and technological achievements. This process mainly includes three stages: the upstream stage, the link of basic research, which is the source of applied research; The midstream stage, that is, the applied research stage, transforms the results of basic research into new technologies; The downstream stage can also be called the realization of innovation value, New technologies are applied to products to form new products and push them to the market to complete the commercialization of innovation results.

\subsection{The Positioning of Science and Technology Innovation Platform in Innovation Chain}

In the innovation chain of science and technology, the innovation content of each link is different. In the upstream stage, that is, the basic research link, basic scientific and technological innovation is carried out,This link is played by pure research platform, resulting in many new scientific discoveries, which either overturn or improve the existing method theory, change the relationship between technical components, and have an impact on enterprises and markets at the 
same time. The midstream stage, that is, the applied research link, carries out applied scientific and technological innovation, which is realized by the industrial technology research platform. The innovation in this stage is based on the innovation achievements in the previous stage and the existing theoretical basis, and produces new technologies or upgrades of existing technologies. The change of technology further affects the production base of products, changes the production process of products and produces new products. Of course, new discoveries not only produce one technology, but may bring about many technological advances. After the end of applied innovation, scientific and technological innovation entered the downstream stage, that is, experimental development and commercialization, which realized the combination of scientific and technological innovation and industrial innovation. New discoveries and technologies can only achieve their mission if they are applied to products and successfully pushed to the market and customers win profits, otherwise it is meaningless to stay in the laboratory. The definition of these three stages is basically the same as Clark's threestage innovation, When new achievements are produced in basic innovation, the subsequent innovation process will change accordingly, and new technology and business innovation will be started [25].

Although the source of scientific and technological innovation extends to basic research, the role of applied research has not weakened at all. At this stage, the innovation achievements change from invisible to tangible, from ideas to reality, and at the same time, new technologies and ideas are produced, which lays the foundation for the formation of new products and processes. In addition, basic research has injected new vitality into the follow-up scientific and technological innovation, and the government, universities and research institutes that conduct basic research have also entered the innovation chain of science and technology, which has improved the efficiency of scientific and technological innovation. Prior to this, there were two main types of scientific and technological innovation platforms engaged in applied research: one was that enterprises built their own laboratories and developed technologies that met the market and corporate profits according to consumer needs; The other is a professional applied research institution specializing in the development of new technologies. There are specializations in the industry, and these two platforms are mainly aimed at technological innovation, while there is a slight lack of stamina for knowledge innovation. The extension of the source of innovation makes universities and scientists enter the chain of technological innovation and $\mathrm{R} \& \mathrm{D}$, and enterprises in the innovation system are also in the R\&D link, The cooperation between the two sides has formed the trend of collaborative innovation of production, education and research [26].
The downstream stage is the key stage of scientific and technological innovation, and the success rate of technological innovation achievement transformation determines the success or failure of innovation, Relying on the business incubation platform, technological achievements are continuously transformed to promote the commercialization of scientific and technological achievements. After entering the stage of experimental development, enterprises still need to continue to innovate in order to fully realize the value of new technologies, At this time, innovation is generally improved innovation combined with market demand. The commercialization of innovation results is mainly measured by whether it can be accepted by the market and obtain profits [9]. Generally speaking, the new technology developed in the applied research link will be directly adopted by the cooperative enterprises and form products or services, and finally realize profits through sales; Technologies that are not needed by cooperative enterprises can be adopted by other enterprises through technology transfer or transaction [22]. In addition, under the current environment of encouraging researchers to start businesses, it is also a commercial way that new technologies are used by researchers to start businesses and form new products. Only the success of this stage marks the success of the whole innovation chain.

In the process of innovation activities, different types of scientific and technological innovation platforms play different roles. Based on the above analysis, we can find that in the basic research stage, that is, the knowledge innovation stage, the pure research platform mainly plays a role in producing the knowledge needed for innovation activities and seeking theoretical breakthroughs; Industrial technology research platform connects knowledge and market, mainly engaged in applied research, and at the same time produces basic research caused by application, which serves the middle reaches of scientific and technological innovation, that is, the stage of technological innovation; The downstream stage mainly involves business model innovation and market innovation, and it needs enterprises to realize the transformation of applied research results into commodities, at which time the business incubation platform plays a role (Figure 2). The knowledge innovation of pure research platform lays the foundation for applied research, and at the same time, applied research will also produce new knowledge. In this process, public service platform provides scientific and technological resources for scientific research and promotes the transformation of scientific and technological achievements. Public service platform and business incubation platform are catalysts for the continuous development of scientific and technological innovation activities. 


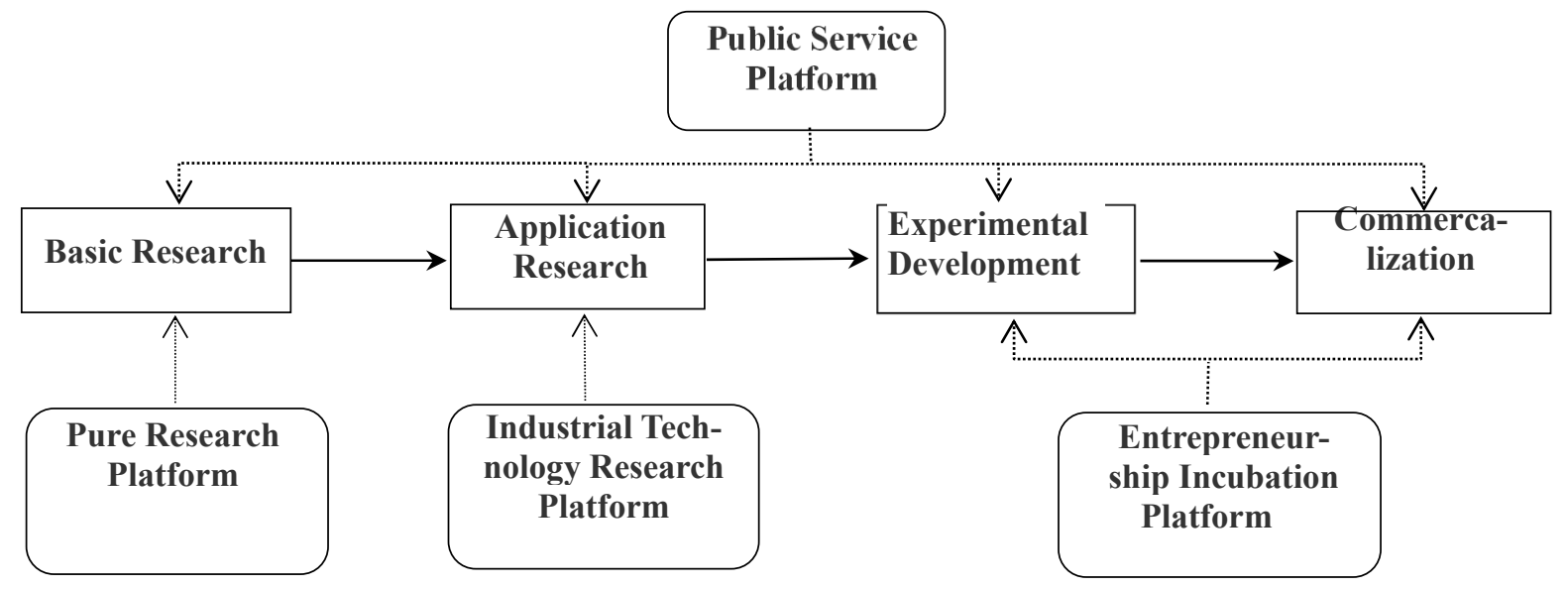

Figure 2 Positioning of Science and Technology Innovation Platform in innovation chain

\section{SCIENCE AND TECHNOLOGY INNOVATION PLATFORM'S VALUE- ADDED ROLE IN THE INNOVATION VALUE CHAIN}

The concept of value chain was first put forward by Porter of Harvard Business School in his book "Competitive Advantage": value chain is used for enterprises to analyze the source of internal competitive advantage, and it is the sum of value activities for enterprises to realize value increment through a series of actions [27]. The existence of value chain divides the strategic activities of enterprises into different but interrelated units. Porter's value chain structure mainly includes basic activities (direct value-added) and auxiliary activities (providing support without creating value by itself). Basic activities include internal and external logistics, production, marketing and service, which are the production process of enterprises and can directly bring value added; Auxiliary activities include purchasing, technology development, personnel management and infrastructure management, which do not directly generate value, but increase value by providing support for basic activities. Differences in value chains among different enterprises form different competitive advantages.

It can be seen that Porter's value chain is composed of the production and operation links of the company and the activities in which various resources are put into operation, with the production process as the main line and other activities providing support. Therefore, based on Porter's thought, applying it to the field of scientific and technological innovation can form the value chain of scientific and technological innovation. In the value chain of scientific and technological innovation, basic research, applied research, experimental development and commercialization constitute basic activities, which are the basic process of realizing innovation and can directly create value and realize value appreciation; Auxiliary activities are activities that invest resources in the process of innovation, ensuring the continuous innovation activities, including human resources management, infrastructure investment (scientific and technological resources), policy support and financial management, These activities can not directly create value, but can realize value increment by providing help for basic activities.

In the past, there were two main ways of innovation activities: first, professional research institutions conducted technical research; Second, enterprises set up laboratories to carry out research and development activities by themselves. This innovative way ignores the importance of basic research, resulting in the break of innovation value chain and poor connection of each link. The total value of innovation results is the result of the whole innovation value chain, but the innovation value chain contains many links, and each link has the formation of innovation value. Innovation process is a process of multiple inputs and multiple outputs, so there are differences in innovation input and innovation income at each stage [21].

\subsection{Innovation Value Chain Upstream: Basic Research Stage}

In the stage of basic research, the research and development objectives are quite different from those of enterprises, and they mainly pursue the improvement of scientific and technological level and the breakthrough of scientific theory,At this time, universities, research institutions and scientists play a major role. Therefore, for the pure research platform, its various inputs are for the continuous scientific research to produce new discoveries and creativity. Therefore, it is necessary to fully guarantee the support of research funds and scientific and technological resources,In addition, the government also needs to provide relevant policy encouragement to attract excellent researchers to enter the platform. In this link, the innovation income can not be simply measured by money, but has great social nature, which is embodied in topics, papers and 
scientific and technological works, The value of these achievements includes the value of supporting activities and the value of knowledge needed for basic research, which will be transmitted down with the innovation value chain.

\subsection{Innovation Value Chain Midstream: Applied Research Stage}

The application research stage is mainly completed by the industrial technology research platform. Industrial technology research platform connects the market and pure research platform, and the construction subjects are diverse, including government, enterprises, research institutes and universities. At this stage, the investment in innovation has changed,In addition to the additional investment in supporting activities and the provision of manpower, material resources and financial resources, the results of basic research also need to be put into it for technological innovation. The discovery and creativity produced by basic research is of great value, and its value cannot enter the technological innovation at one time, but generally enters the applied research stage in several parts. According to Marx's value formula, the value of products consists of variable capital, constant capital and surplus value $(\mathrm{W}=\mathrm{c}+\mathrm{v}+\mathrm{m})[28]$. In innovation activities, fixed capital generally refers to capital investment and material resources investment; Variable capital consists of researchers engaged in research and development activities; Surplus value is expressed as the value of new inventions and discoveries, which together constitute the value of innovative achievements. Of course, the value of innovation achievements of pure research platform is potential, and the industrial technology research platform connects the market and basic research, and strives to realize the market value of innovation achievements and realize the value increment of innovation achievements.

\subsection{Downstream of Innovation Value Chain: Experimental Development and Commercialization Stage}

After entering the downstream stage of innovation value chain, the output of upstream and midstream enters the value system of innovation achievements as new input, which realizes value through transfer on the one hand and product on the other. Technology transfer is mainly manifested in the realization of its value in the form of remuneration of intellectual property rights, and the acquisition of the right to use new technologies through transactions or one-time buyout. For untransferred technologies, they will enter the business incubation platform and continue to add value. Entrepreneurship incubation platform provides excellent environment and conditions for the transformation of scientific and technological achievements and innovation of scientific and technological enterprises, including not only capital and hardware facilities, but also information resources, policies, laws and other software support, helping enterprises to apply new technologies and realize their value. In this process, the newly invested capital is added to the innovation value chain system, which not only realizes the potential value of the innovation achievements in the upstream stage, but also realizes commercialization by continuously running in with the market. Of course, to realize commercialization, we should not only improve and revise the products, but also adjust the business model to help the products be accepted by the market. These behaviors directly and indirectly promote the value increment of innovation achievements. In addition, the state strongly supports scientific and technological personnel to start their own businesses, and scientific research personnel start their own businesses with their own innovation achievements, which is also a way to realize the commercialization of innovation achievements. Scientific and technical personnel can effectively combine market demand with $\mathrm{R} \& \mathrm{D}$ demand and improve the application value of innovation achievements. For such entrepreneurs, there will be venture capitalists to invest and help them start businesses. This way can increase the value of innovation achievements, and at the same time, it should bear the risk of starting a business. Generally speaking, the closer to the market, the smaller the potential benefits and the more intense the competition; The farther away from the market, the smoother the competition, and the greater the potential benefits [29]. In addition to realizing the potential value of innovative achievements, the participation of venture capitalists will also expand its market value to ensure the success of entrepreneurship. These behaviors will increase the value of innovation achievements.

Throughout innovation chain, public service platforms provide all kinds of resources needed for innovation activities, and several kinds of scientific and technological innovation platforms cooperate with each other to promote innovation activities to continue. However, the value of innovation achievements can not be simply understood as the sum of manpower, material resources and financial resources on the platform, but also includes the total value of multi-stage outputs and various innovative behaviors (Figure 3). The development of each link needs the promotion of corresponding capital,The key to the entry of basic research into applied research lies in the transformation of knowledge innovation achievements, At this time, the role of knowledge capital is the prerequisite for technological innovation; When applied research enters the downstream link of experimental development and commercialization, the key lies in technology adoption, business model innovation and market innovation combined with market demand,At this time, financial 
capital and human capital of enterprises play a huge role. Whether it is knowledge innovation in the early stage, business innovation in the later stage, or marketing, it is aimed at maximizing the value of innovation achievements, and the value of innovation achievements is constantly superimposed in this process, finally realizing value-added. At the same time, the social and economic benefits brought by the flow of scientific and technological achievements through the chain shorten the distance between science and technology and economy, enhance the closeness of each link, stimulate new social and market demands and start a new round of innovation.

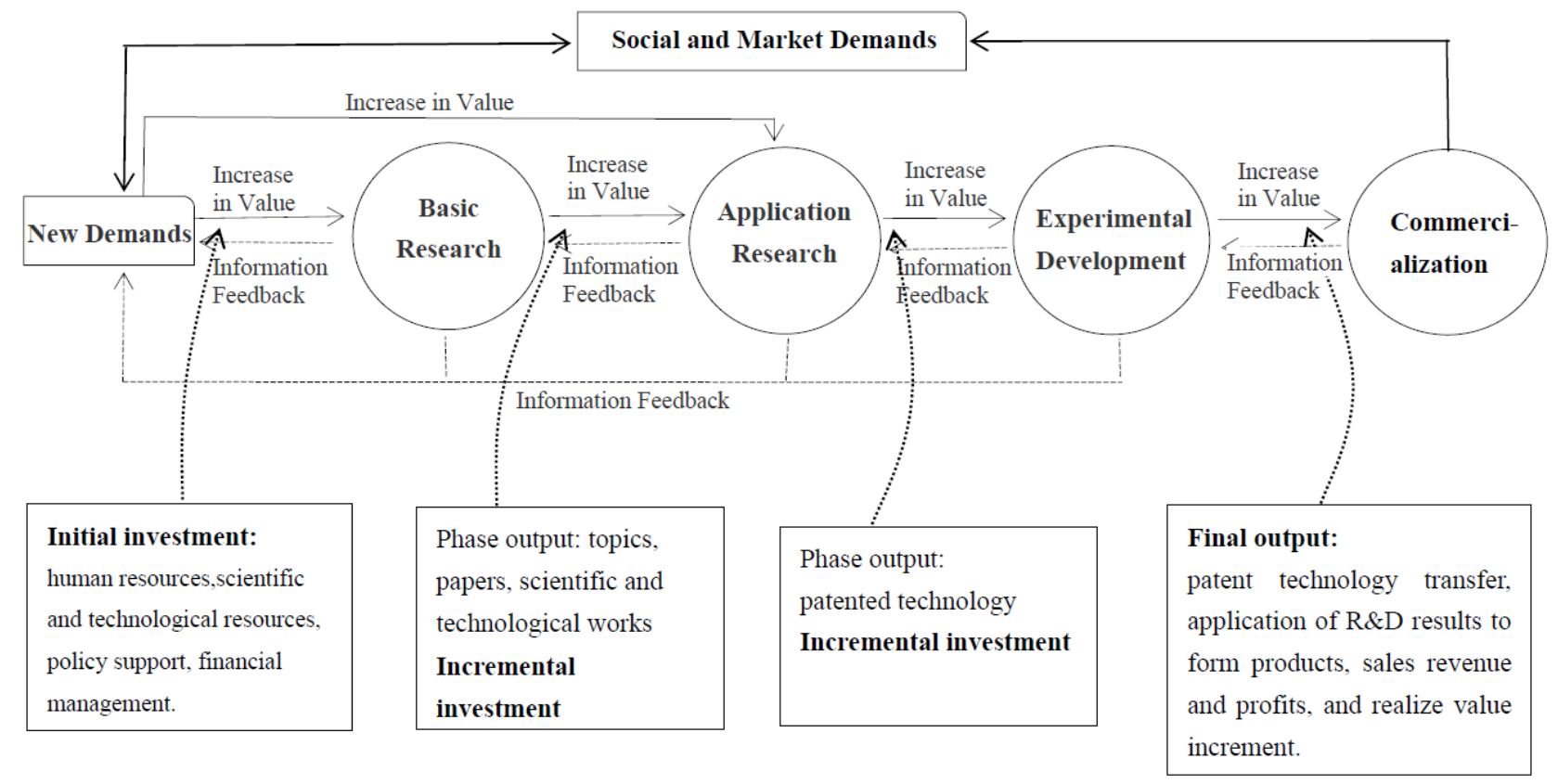

Figure 3 Value-added role of science and technology innovation platform in value chain

\section{ANALYSIS OF VALUE FLOW BETWEEN SCIENTIFIC AND TECHNOLOGICAL INNOVATION PLATFORMS}

Commercialization of scientific and technological innovation achievements is a comprehensive system with multiple subjects and complex processes. The traditional transformation process generally consists of technology development, technology popularization and application,Science and technology intermediaries transfer the achievements of universities and research institutes to enterprises for further promotion. This way makes the information asymmetry between universities, research institutes and enterprises, affects the transformation of scientific and technological achievements and enterprise innovation, and breaks technology and demand [30]. Innovation value chain makes each stage of scientific and technological innovation interlocking, and each link can directly carry out achievement transfer and demand docking through scientific and technological innovation platform, and each stage and participants have their own value pursuit,Therefore, the cooperation between scientific and technological innovation platforms and the mutual benefit and win-win between production, education and research are of great significance to the ultimate success of innovation activities.
The key of innovation activities in the value chain lies in the transition of each stage and the promotion of capital. Pure research platform mainly provides knowledge capital for innovation value chain, which is the source of innovation activities and the driving force of economic growth. The new growth theory regards knowledge as an independent variable in the growth model, and the theory holds that the economic growth brought by knowledge lies not only in its own valueadded, but also in the fact that knowledge can spread to other factors such as capital and manpower to promote the increase of income [31]. Knowledge is the source of promoting technological progress, and its value will flow along the innovation chain to the link of technological innovation. In the process of transferring knowledge resources between pure research platform and industrial technology research platform, the goal of knowledge innovation will be adjusted according to the feedback of technological innovation stage. Of course, not all knowledge resources used for technological innovation are newly created,Pure research platform and public service platform continuously transfer value to obtain existing knowledge capital, while public service platform will also bring new knowledge generated by pure research platform into the database to constantly update resource reserves, This process does not generate value increment, but simply exchange value. The task of knowledge innovation is mainly completed by universities and research institutes. As the 
center of knowledge gathering and talent training in China, colleges and universities have a strong subject knowledge base and talents with these knowledge, which can realize the "point-to-point" connection between research content and professional disciplines,After entering the R\&D link, they have formed a situation of collaborative innovation of production, education and research, which constitutes an innovation system for enterprises, governments and academia to communicate with each other [32]. Scientific research institutes accurately grasp the direction of China's scientific and technological innovation, and have strong knowledge sensitivity, keenness and abundant scientific and technological resources to effectively promote innovation.

Knowledge capital generated by pure research platform will not enter the stage of technological innovation at one time, but will play a role in innovation as stock capital for many times. After the intellectual capital entered the applied research stage, the industrial technology research platform began to play its role. In the innovation value chain, the industrial technology research platform is the most dynamic, derivative and plastic key node. A number of innovative product series and innovative knowledge can be derived from the industrial technology research platform, forming a tree-like branching innovation value chain network system [33]. After undertaking the upstream knowledge capital, we began to carry out technological innovation. It should be pointed out that not only the knowledge capital is spillover, but also the new technology produced is spillover,Moreover, the incubation technology belongs to venture capital and may not succeed, so personal investment is often unable to bear it. Therefore, the government has the responsibility to participate in the process of knowledge innovation and technological innovation, and provide policy support, capital support and other resources to promote technological innovation. Of course, government investment is only a guiding investment and cannot replace enterprises. Because the industrial technology research platform should consider the market demand and the executive power of enterprises on the one hand, and the advancement and reality of knowledge capital on the other hand, it needs the participation of universities, research institutes and enterprises. And each subject on the platform will obtain the required resources in the innovation activities according to their own comparative advantages, effectively avoiding the disconnection between economy and science and technology [34]. These inputs will eventually be reflected in the new technologies produced, and some of the value will flow to the next link along the innovation chain, while some of the value will flow back to the pure research platform and the business incubation platform, which will generate information feedback.
When the value of innovation achievements flows to the downstream stage, the business incubation platform is added as a catalyst to promote scientific and technological innovation. New knowledge capital and technology capital attract investment to carry out new projects or start businesses in science and technology. At this stage, scientific and technological innovation should not only continue to carry out innovative activities, but also consider the influence of market activities, business models and enterprise capital. Besides material capital, human capital in enterprises is the key to the success of innovation. The final realization of commercialization is measured by the sales revenue of new products, so the management, innovation and sales talents largely determine the success or failure of commercialization of innovative achievements [35]. Enterprises in the business incubation platform will also improve and innovate the achievements of the industrial technology research platform to adapt to the enterprises and the market to realize their potential value. In this link, innovation and entrepreneurship become an organic whole, the overall value of the enterprise is improved, and the value of innovation achievements is added. At this point, the commercialization of scientific and technological innovation is completed, and the new market reaction and achievement information will be fed back to the starting point of the innovation value chain, starting a new round of innovation.

\section{CONCLUSION}

Innovation value chain is an aggregate of organizational node chains, which regards the process from the source of scientific and technological innovation to large-scale development and finally commercialization as diversified innovation subjects with their own needs and interests as a link through the scientific and technological innovation platform [33]. Its particularity has the effect of increasing returns and circulating accumulation on innovation subject, innovation environment and policy support [36]. In this process, the value flow of each link has corresponding value pursuit and function. The value of innovation achievements flows positively along innovation chain, promoting the transformation of scientific and technological achievements and accelerating the realization of social and market needs; Reverse flow will feed back the demand of the next link to the upstream, making the upstream $R \& D$ innovation more targeted and more suitable for the demand. At the same time, the value flow in the chain is not single, but can flow across links and platforms. The downstream information can be directly transmitted to the pure research platform across the industrial technology research platform, thus realizing the network of value transmission and effectively avoiding the errors caused by the linear transmission of information. 
However, the market is changing rapidly, and the construction of scientific and technological innovation platform is still in the process of continuous exploration. The value chain of scientific and technological innovation has no fixed structure, and the quantitative evaluation of its value transfer needs systematic observation and follow-up research. Whether the value creation process of science and technology innovation value chain mentioned in this paper can be applied to the future development of science and technology innovation needs more case analysis and further empirical research to test and discuss.

\section{ACKNOWLEDGMENT}

This work was supported by National Philosophy and Social Science Fund Project of China(19BGL028).

\section{REFERENCES}

1. M. Coccia and S. Rolfo. "Strategic Change of Public Research Units in Their Scientific Activity." Technovation 28.8(2008):485-494.

2. C. Zhihui. "Research on Connotation, Characteristics and Development of Science and Technology Innovation Infrastructure." Science and Technology Management Research 33.17(2013):34-37.

3. M. Yinjun, J. Diao and J. Luo . "Research on Open Innovation of Multi-agent Participation in New R\&D Institutions: From the Perspective of Strategic Niche Management." Science and Technology Management Research 39.15(2019)22:28.

4. Y. Zhang, K. Chen, and X. Fu . "Scientific effects of Triple Helix interactions among research institutes, industries and universities." Technovation 8687(2019):33-47.

5. D. H. Lee, I. W. Seo, H. C. Choe, H. D. Kim. "Collaboration network patterns and research performance: the case of Korean public research institutions." Scientometrics 91.3(2012):925-942.

6. H. X. Chen, C. Jiang, Y. Yuan, S. B. "Research on the transfer and transformation mode of scientific and technological achievements of new R\&D institutions based on the new Pasteur quadrant _ Taking Jiangsu Industrial Technology Research Institute as an example." Science and Technology Progress and Countermeasures 35.11(2018):36-45.

7. P. Ganotakis, J. H. Love. "The innovation value chain in new technology-based firms: Evidence from the U.K." Journal of Product Innovation Management 29.5(2012):p.839-860 .

8. X. Chen, Z. Liu, Q. Zhu. "Performance evaluation of China's high-tech innovation process: Analysis based on the innovation value chain." Technovation: The International Journal of Technological Innovation, Entrepreneurship and Technology Management 7475(2018):42-53.

9. S. Roper, J. Du, J. H. Love. "Modelling the innovation value chain." Research Policy 37.6(2008):961-977 .

10. H. Meyer, J. M. Utterback. "The product family and the dynamics of core capability." Sloan Management Review (1993):29-47 .

11. D. Robertson, K. T. Ulrich. "Planning for product platform." MIT Sloan Management Review 39.4(1998):1-5.

12. P. Mohnen, L. Roller, Hendrik. "Complementarities in innovation policy." European Economic Review 49.6(2005):1431-1450.

13. Q. Sun. "Research on the Network Evolution Process and Mechanism of Regional Science and Technology Innovation Platform." China Science and Technology Forum 1(2012):96-101.

14. Reppy, Judith. :The Economic Laws of Scientific Research. Terence Kealey." Isis 91.3(2000):578-579.

15. V. Bush. "Science- the Endless Frontier: A Report to the President on a Program for Postwar Scientific Research." Washington, D C: National Science 1945( Reprinted in 1990).

16. S. J. Kline, N. Rosenberg. "An Overview of Innovation." The positive sum strategy. Harnessing technology for economic growth (1986):17-320.

17. D. E. Stokes. "Pasteur's Quadrant: Basic Science and Technological Innovation." Washington, DC: Brookings Institution Press (1997): 46-54.

18. J. A. Schumpeter. "Capitalism socialism and democrazy.5th edition." London: George Allen and Unwin Press (1976).

19. C. Freeman. "Continental, national and sub-national innovation systems-Complementarity and economic growth." Research Policy 31.2(2002).

20. Y. Z. Gou, F. Lin. "Research on new scientific research institutions from the perspective of innovation value chain — Taking Huada Gene as an example." Science and Technology Progress and Countermeasures 32.2(2015):8-13.

21. Y. Z. Yu, D. Y. Liu. "Research on the Path of Improving Regional Innovation Efficiency in China from the Perspective of Innovation Value Chain." Scientific Research Management 35.5(2014):27-37.

22. C. Sun, C. Wang, Q. Y. Zhang. "Research on the Spatial Interaction Effect between Technological Innovation and Producer Services Agglomeration from the Perspective of Innovation Value Chain." Scientific and Technological Progress and Countermeasures 35.22(2018):55-62.

23. J. P. Xi. "Struggling for Building a World Powerful Country in Science and Technology — Speech at National Science and Technology Innovation Conference, Academician Conference of Chinese Academy of Sciences and Ninth National Congress of China Association for Science and Technology." Association for Science and Technology Forum 6(2016):4-9. 
24. M. Meyer. "Tracing knowledge flows in innovation systems." Scientometrics 54.2(2002):193-212.

25. Clark. "The mode of enterprise technological innovation ." in Liao $\mathrm{Li}$ et al, the journey of seeking wisdom, Beijing: Peking university press (2000):282.

26. Y. X. Hong. "Analysis of the stage of scientific and technological innovation and its innovation value chain ." Economist 4(2017):5-12.

27. M. E. Poter. "Competitive advantage." New York: Free Press (1985):230-245.

28. M. Karl. "Capital.” Penguin Classics (1990).

29. Y. X. Hong. "Analysis of the stage of scientific and technological innovation and its innovation value chain ." Economist 4(2017):5-12.

30. Y. H. Ruan, X. A. Xu, B. Wang, Z. L. Du, S. M. Tan Simin. "Analysis of the technology transfer and transformation mode of new R\&D institutions from the perspective of collaborative innovation

Taking Cloud Computing Center of Chinese Academy of Sciences as an example ." Research on the Development Strategy of Science and Technology Innovation 2.3(2018):85-88.

31. H. X. Guo. "Computing of the contribution rate of scientific and technological progress to economic growth in Chinese regions." Expert Systems with Applications 39.10(2012):8514-8521.

32. OECD. "The Knowledge-based Economy." General Distribution Ocde/gd 96(1996).

33. G. Huang, J. P. Xu, Mars. "Science and technology value chain and innovation subject link mode." China Soft Science 6(2006:67-75.

34. T. Kodama. "The role of intermediation and absorptive capacity in facilitating university-industry linkages--An empirical study of TAMA in Japan." Research Policy 37.8(2008):1224-1240.

35. X. Chen, Z. Liu, Q. Zhu. "Performance evaluation of China's high-tech innovation process: Analysis based on the innovation value chain." Technovation (2018):74-75.

36. Y. Zhang, S. H. Zhong. "How to customize the content of regional innovation policy effectively - Based on forward-looking public policy analysis." China Science and Technology Forum 9(2019):25-33. 